\title{
Assessment of Myocardial Function in Birth Asphyxia
}

\section{Goel M${ }^{1}$, Gohiya Poorva ${ }^{2}$, Yadav BS ${ }^{3}$}

${ }^{1}$ Dr Manjusha Goel, Associate Professor of Pediatrics, ${ }^{2}$ Dr Poorva Gohiya, Assistant Professor of Pediatrics, ${ }^{3}$ Dr B S Yadav, Professor in Cardiology. All affiliated with Gandhi Medical College, Bhopal, MP, India

Address for Correspondence: Dr Manjusha Goel, Email: manjushagoel@rediffmail.com

\begin{abstract}
Introduction: Perinatal asphyxia has effect on various body systems and cardiovascular system is one of them. We have assessed myocardial function in Birth asphyxia by clinical evaluation, electrocardiogram \& echocardiography. Design: Cross sectional observational study. Setting - Hospital based. Method: 20 severely asphyxiated \& 20 moderately asphyxiated newborns were compared with 20 normal newborns. Serial Electrocardiograms were taken on $1^{\text {st }}, 3^{\text {rd }} \& 7^{\text {th }}$ day of life. Left ventricular Ejection Fraction, diameters \& \% shortening were calculated by echocardiogram. Results: Respiratory distress was present in $70 \%$ of severely asphyxiated \& $25 \%$ of moderately asphyxiated newborns. Shock was present in $75 \%$ of severely asphyxiated newborns and $15 \%$ of moderately asphyxiated newborns. $20 \% \& 15 \%$ newborns with severe asphyxia had pansystolic murmur \& congestive cardiac failure respectively. Abnormal ST segment was present in $40 \% \& 35 \%$ newborns with severe \& moderate asphyxia respectively within 24 hours. T wave changes were seen in $70 \%, 50 \% \& 10 \%$ newborns with severe, moderate asphyxia \& control respectively in the first reading. LVED diameter, LVES diameter was higher in asphyxiated newborns. Ejection fraction were reduced in asphyxiated newborns. Conclusion: ECG is a very sensitive indicator for establishing the diagnosis of myocardial ischaemia. Echocardiographic evaluation substantiates the findings of myocardial dysfunction in birth asphyxia.
\end{abstract}

Keywords: Birth asphyxia, myocardial function.

\section{Introduction}

Perinatal asphyxia is a major cause of morbidity and mortality in India. It is an insult to the fetus or newborn due to hypoxia \& poor perfusion to various organs ${ }^{1}$. Perinatal hypoxia contributes greatly to perinatal and neonatal morbidity \& mortality. Neurologic dysfunction is usually the most obvious presentation \& its overwhelming

Manuscript received: $13^{\text {th }}$ Sept 2013

Reviewed: $26^{\text {th }}$ Sept 2013

Author Corrected: $19^{\text {th }}$ Oct 2013

Accepted for Publication: $30^{\text {th }}$ Oct 2013 nature often distracts our attention from the presence of other organ system dysfunction. Myocardial ischemia following perinatal stress and with unobstructed coronary arteries is getting wider recognition. The effect of asphyxia on myocardium was described as early as 1935 by Hori H. Imai ${ }^{2}$. Myocardial ischemia has been demonstrated by thallium 201 myocardial perfusion scans $^{3}$, elevated serum C P K M B isoenzyme ${ }^{4,5}$ \& histopathologically ${ }^{6}$ at autopsy $\&$ in electrocardiogram in the past.

Available online at: www.ijmrr.in 228 | P a g e




\section{Material \& Methods}

In this study 40 neonates with moderate and severe asphyxia were clinically evaluated and their myocardial function was assessed with the help of serial electrocardiogram and echocardiogram. 20 newborns were taken as a control. Newborns with mild asphyxia were excluded. The neonates were divided into 3 groups according to HIE staging of Sarnat \& Sarnat. The criteria for inclusion in study were based on abnormal neurological examination $\&$ any or more of the following features:

(i) Documentation of intra partum fetal distress through recognition of abnormal fetal heart rate patterns with or without passage of meconium.

(ii) The presence of immediate neonatal distress as evidenced by a low one minute $(<7)$ Apgar score.

(iii) The need for immediate neonatal resuscitation.

Echocardiography was done within 72 hours of birth with a transducer of $3.2 \mathrm{MHz}$. Ejection fraction (EF) was calculated by the formula ${ }^{7}$ :

\section{LVEDV - LVESV}

100

\section{LVEDV}

Where:

LVEDV and LVESV are Left ventricular end diastolic and end systolic volume respectively. \% of shortening of left ventricle was calculated by:

LVEDD - LVESD

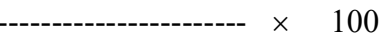

LVEDD
The LVEDD \& LVESD were measured by 2D study on ALOKA SSD - 630 Echo machine.

\section{Results}

\section{Clinical Manifestations}

$70 \%$ of severely asphyxiated newborns \& $25 \%$ of moderately asphyxiated newborns had respiratory distress manifested by tachypnoea, intercostal, subcostal \& suprasternal recession, movement of alae nasi, expiratory grunt \& cyanosis.

$75 \%$ of severely asphyxiated \& $15 \%$ of moderately asphyxiated newborns were found in shock clinically manifested by weak brachial and femoral pulses, cold extremities, pallor, hypothermia, increased capillary refilling time $(>3 \mathrm{sec})$.

Pansystolic Murmur was present in $20 \%$ of newborns with severe asphyxia \& congestive cardiac failure in $15 \%$ newborns with severe asphyxia as shown in Table 1 . Features of pulmonary hypertension were seen in 10 newborns with severe and in 2 newborns with moderate asphyxia.

The mean age of presentation of shock was within 12 hours. CCF and murmur were seen at around $3^{\text {rd }}$ day.

It was observed that $95 \%$ of severely asphyxiated newborns had one more clinical manifestations of myocardial dysfunction.

Similarly in the group with moderate asphyxia $40 \%$ of the newborns had clinical manifestations. 
Table 1: Myocardial Dysfunction in Birth Asphyxia.

\begin{tabular}{|l|l|l|}
\hline Clinical sign & Group A & Group B \\
\hline Shock & $75 \%$ & 15 \\
\hline Respiratory Distress & $70 \%$ & $25 \%$ \\
\hline Murmur & $20 \%$ & Nil \\
\hline CCF & $15 \%$ & Nil \\
\hline
\end{tabular}

\section{Electrocardiography}

Serial electrocardiogram was taken on $1^{\text {st }}, 3^{\text {rd }} \& 7^{\text {th }}$ day. 3 newborns had heart rate below 100 in the first reading. Prolonged QRS (>0.06 sec) was present in $15 \%$ of newborns with severe asphyxia out of which $66.6 \%$ had a RBBB and $33.3 \%$ had LBBB. $10 \%$ of newborn in the moderate asphyxia group had RBBB.

Abnormal Q wave (amplitude of Q 25\% or more of following R wave or Q wave $4 \mathrm{~mm}$ of more in depth or $>0.02$ sec was seen in $10 \%$ of newborns in 1 st reading $\& 2$ nd reading $\&$ in none in 3 rd reading in group A. In group B abnormal Q wave were seen in 30\% newborns in 1st reading, $26.3 \%$ in 2 nd reading \& $13.3 \%$ in 3 rd reading. In the control group abnormal Q was seen in 5\% newborns in 1st reading. Abnormal ST segment (ST segment depression or elevation $1 \mathrm{~mm}$ or more in standard leads or $2 \mathrm{~mm}$ or more in chest leads) was found in $40 \%$ in 1 st reading, $30 \%$ in 2 nd reading \& $14.28 \%$ in 3 rd reading in severely asphyxiated newborns. Amongst the newborns with moderate asphyxia, abnormal ST segment was seen in $35 \%$, $26.5 \%, \& 6.6 \%$ in 1 st, 2 nd, \& 3rd readings respectively. No abnormality in ST segment was observed in the control group.

$\mathrm{T}$ wave changes (Flat or inverted $\mathrm{T}$ wave except in avR) was seen in 70\%,60\%, \& $14.8 \%$ severely asphyxiated newborns in 1 st, 2nd, 3rd readings respectively as shown in Table 2 . It was observed that the $\mathrm{T}$ waves returned to normality in $8.3 \%$ of asphyxiated newborns within $24-72$ hours $46.6 \%$ in 1 week..

Table 2: T wave changes in Birth Asphyxia

\begin{tabular}{|l|l|l|l|l|l|l|}
\hline \multirow{2}{*}{ Group } & \multicolumn{2}{|l|}{$\mathbf{1}^{\text {st }}$ Reading } & \multicolumn{2}{l|}{$\mathbf{2}^{\text {nd }}$ Reading } & \multicolumn{2}{l|}{$3^{\text {rd }}$ Reading } \\
\cline { 2 - 7 } & No. of cases & Percentage & $\begin{array}{l}\text { No. of } \\
\text { cases }\end{array}$ & Percentage & $\begin{array}{l}\text { No. } \\
\text { cases }\end{array}$ & Percentage \\
\hline A & 14 & 70 & 6 & 60 & 1 & 14.28 \\
\hline B & 10 & 50 & 9 & 47.4 & 2 & 13.5 \\
\hline C & 02 & 10 & 0 & 0 & 0 & 0 \\
\hline
\end{tabular}

\section{Echocardiography}

The mean LVED diameter and the mean LVES diameter in asphyxiated newborn were higher than in the control group. The higher LVED \& LVES dimensions in asphyxiated newborns as compared with controls were statistically significant $(\mathrm{p}=0.03$ $\& 0.005$ respectively ). Similarly the mean ejection fraction and \% shortening of Left ventricle were less in the asphyxiated newborns as compared with the control group as shown in Table 3. 
Table 3: LVED, LVES diameter, \% shortening of Left Ventricle\& Ejection Fraction in various groups

\begin{tabular}{|l|l|l|l|l|}
\hline Groups & LVED in mm & LVES in mm & $\begin{array}{l}\text { shortening of } \\
\text { Left ventricle }\end{array}$ & Ejection fraction \\
\hline A & 17.3 & 10.85 & $33.6 \%$ & $64.5 \%$ \\
\hline B & 15.6 & 9.25 & $36.7 \%$ & $70.5 \%$ \\
\hline C & 14.3 & 8.2 & $43.5 \%$ & $81.5 \%$ \\
\hline
\end{tabular}

The newborns were managed symptomatically with inotropic support. 65\% (13) of severely asphyxiated \& 27\% (5) of moderately asphyxiated newborns expired. More extensive changes were present in the electrocardiogram of many of the asphyxiated newborns who expired \& also most of these newborns had reduced ejection fraction \& \% shortening of left ventricle.

\section{Discussion}

Although the exact pathogenesis of myocardial dysfunction in birth asphyxia is still not clear, most workers have enumerated the role of hypoxia induced pulmonary vasoconstriction as the main precipitating cause of disturbed circulatory dynamics. The myocardium may also be affected by acute perinatal blood volume changes of either extreme, by metabolic derangements or by electrolyte disturbances. The area of myocardium affected most by asphyxia is the sub endocardial region as it is closest to the high pressure of the ventricular cavity \& most distant from the coronary blood supply. Serial ECG changes have been linked to such transient myocardial ischemia in the newborn and it is a sensitive indicator for establishing the diagnosis of myocardial ischemia.

Electrocardiographic changes in birth asphyxia have similarly been described by Richard D. Rowe ${ }^{8}$, S.R. Daga $^{9}$, H. Gidwani ${ }^{10}$ etc in the past. Reduced ejection fraction and increased left ventricular end diastolic and end systolic dimensions in asphyxiated newborns as observed by us have also been reported by P.B. Tsivyan ${ }^{11}$, John P. Finley ${ }^{3}$ and I Barberi ${ }^{12}$

\section{Conclusion}

Although some of the asphyxiated infants with myocardial dysfunction may die in the immediate neonatal period, conservative management is all that is required to salvage most of such babies. Although the extensive changes seen show the vulnerability of the neonatal tiny heart to birth asphyxia, complete recovery within weeks or months have been demonstrated on clinical, electrocardiographic, angiocardiographic studies in these babies, but still these newborns should be regularly followed up to determine whether the transient ischemia has any relationship with childhood disorder of unknown etiology like cardiomyopathies, Mitral Vave prolapse (MVP) etc.

\section{Funding: Nil}

\section{Conflict of interest: Nil}

\section{Permission from IRB: Yes}

\section{References}

1. Cloherty JP, Snyder EY. Perinatal asphyxia. Manual of Neonatal Care. 7Edition,Wolters Kluwer Publication 2012;55:711-27

2. Hori H ,Imami M, Safo M. On the Electrocardiogram of Newborn, Second report on the ECG of the asphyxiated newborn,Jap .J.Obst.Gynaec.1935;18:333-9.

3.Finley JP, Howman-Giles RB, Gilday DL, Bloom KR, Rowe RD. Transient myocardial ischemia of the newborn

Available online at: $\underline{\text { www.ijmrr.in }} \quad 231$ | $\mathrm{P}$ a g e


infant demonstrated by thallium myocardial imaging. J Pediatr. 1979 ;94(2):263-70.

4.Jyoti Agarwal, Gauri S Shah, Prakash Poudel, Nirmal Baral, Ajay Agrawal and Om $\mathrm{P}$ Mishra. Electrocardiographic and enzymatic correlations with outcome in neonates with Hypoxic Ischaemic Encephalopathy. Italian journal of Pediatrics.2012;38;33.

5.Tapia-Rombo CA, Carpio-Hernández JC, SalazarAcuña AH, Alvarez-Vázquez E, Mendoza-Zanella RM, Pérez-Olea V, Rosas-Fernández C. Detection of transitory myocardial ischemia secondary to perinatal asphyxia. Arch Med Res. 2000;31(4):377-83.

6. Bancalari A, Otero C, Bello P, Soto G, Pandolfi E, León L. Myocardial damage following neonatal severe asphyxia. Rev Chil Pediatr. 1991;62(4):232-7.

7.William F Armstrong, Thomas Ryan. Feigenhaum's Echocadiography $7^{\text {th }}$ edition. Lippincott Williams and Wilkins, ;Philadelphia 2012.
8. Rowe R.D. Hoffman T. Transient myocardial ischemia of the newborn infant: a form of severe cardiorespiratory distress in full tern infants. J Paediatr.1972; 81(2):243-50.

9. Daga SR, Wagholokar UL. Clinicopathological correlation in neonatal myocardial ischaemia. Indian $\mathrm{J}$ Pathol Microbiol. 1986; 29(3):297:301.

10. Gidvani CH, Raju U, Chandar V, Ghosh B, Wilson CG. ECG changes in asphyxia neonatorum. India Pediatr. 1990;27(11):1177: 81 .

11. Tsivyan PB, Vasenina AD. Left ventricular systolic and diastolic function in term infants after mild perinatal asphyxia. Eup. J. obstet Gynecol Reprod Biol. 1991;40(2):105- 10 .

12. I Barberi, M P Calabrò, S Cordaro, E Gitto Sottile A, Prudente D, Bertuccio G. Myocardial ischaemia in neonates with perinatal asphyxia, electrocardiographic, echocardiographic and enzymatic correlations. European Journal of Pediatrics . 1999; 158(9):742-7.

\section{How to cite this article?}

Goel M, Gohiya Poorva, Yadav BS. Assessment of Myocardial Function in Birth Asphyxia. Int J Med Res Rev 2013;1(5): 228-232. doi: 10.17511/ijmrr.2013.i5.03. 